\title{
Health Promotion for Tobacco Control
}

\author{
Carole Mireille Mende B.D. \\ Nelson Mandela College of Government \& Social Sciences, \\ Southern University and A\&M College, LA, USA
}

\begin{abstract}
Tobacco consumption is one of the leading causes of death worldwide and has been correlated with negative health consequences. Tobacco use also burdens the global economy This paper is an overview of health promotions for tobacco control in the Louisiana. This paper is not intended to provide an exhaustive literature review but to highlight health on the basis for discussing future research directions. An increase in health promotion efforts about the detrimental health effects of tobacco use may result in higher levels of knowledge about the negative effects of smoking. Awareness of populations through health promotion strategies is a primary tool for tobacco prevention and cessation. An education of the public is an important part of the efforts to prevent the initiation of smoking use and encourage smoking cessation.
\end{abstract}

Keywords: Health promotion, tobacco, tobacco control

DOI: $10.7176 /$ PPAR/10-1-07

Publication date: January $31^{\text {st }} 2020$

\section{Introduction}

Tobacco is a product prepared from the leaves of a tobacco plant by curing them. Tobacco contains the alkaloid nicotine which is a stimulant. Tobacco use is the number one cause of preventable death in the United States and around the world (WHO, 2008). According to research, in the year 2015, 2.5 percent of adults in Louisiana used e-cigarettes, 2.4 percent used smokeless tobacco and 2.1 percent smoked cigars (Campaign for Tobacco-Free kids, 2017). In 2016, 22.8 percent of adults smoked. Nationally, the rate was 17.1 percent (CDC, 2017). In 2017, 12.3 percent of high school students smoked on at least one day in the past 30 days. Nationally, the rate was 8.8 percent, 12.2 percent of high school students used e-cigarettes, 10.7 percent used smokeless tobacco and 11.0 percent smoked cigars on at least one day in the past 30 days. Nationally, the rates were 13.2 percent, 5.5 percent and 8.0 percent, respectively. Louisiana received $\$ 477.4$ million (estimated) in tobacco settlement payments and taxes in fiscal year 2018 (Campaign for Tobacco-Free kids, 2018). Of this, the state allocated \$5.8 million in state funds to tobacco prevention in fiscal year 2018, just 9.7 percent of the Centers for Disease Control and Prevention's annual spending target. Smoking-related health care costs: \$1.89 billion per year Smoking-related losses in productivity: $\$ 2.49$ billion per year Smokeless tobacco is taxed at 20 percent of the invoice price and smoking tobacco is taxed at 33 percent of the invoice price (Campaign for Tobacco-Free kids, 2018). Cigars are taxed between 8 percent and 20 percent, depending on the manufacturer's invoice price. E-cigarettes and vapor products are taxed at 5 cents per milliliter of consumable nicotine liquid solution (American Lung Association, 2018)

Tobacco use is the greatest cause of preventable death globally. $50 \%$ of people who use tobacco die from the results of this use. Tobacco use leads most commonly to diseases affecting the heart, liver and lungs. Smoking is a major risk factor for heart attacks, strokes, chronic obstructive pulmonary disease and so on (CDC, 2006).

When someone smokes a cigarette, all of the smoke doesn't go into their lungs. it goes into the air and anyone in that environment can breathe it. Secondhand smoke causes numerous health problems in both adults and children alike, including more frequent and severe asthma attacks, respiratory infections, ear infections, cancer of the lungs, cancers of the larynx and mouth. It is the combination of smoke from the burning end of a cigarette and the smoke breathed out by smokers People who do not smoke suffer from the effects of breathing second-hand smoke. In about 8 to 20 minutes physical reactions can occur that are linked to heart disease and stroke. These reactions include increased heart rate, less oxygen to the heart, and constricted blood vessels that increase blood pressure and make the heart work harder (Frank, 2012).

A comprehensive and rigorous awareness of populations through health promotion strategies is/are the primary tools for tobacco prevention and cessation. Public education is an important part of the efforts to prevent the initiation of smoking use and encourage smoking cessation. An increase in health promotion efforts about the detrimental health effects of tobacco use may result in higher levels of knowledge about the negative effects of smoking and in turn could increase the desire to quit and lead to a subsequent quitting among users. By increasing the knowledge about smoking cessation methods, health professionals can support and encourage the large majority of smokers who want to quit (Golechha, M, 2016) 


\section{LOUISIANA REPORT CARD 2018}

\begin{tabular}{|l|l|}
\hline Tobacco Prevention and Control Program Funding & F \\
\hline FY2018 State Funding for Tobacco Control Programs: & $\$ 5,805,725^{*}$ \\
\hline FY2018 Federal Funding for State Tobacco Control Programs: & $\$ 1,233,018^{* *}$ \\
\hline FY2018 Total Funding for State Tobacco Control Programs: & $\$ 7,038,743$ \\
\hline CDC Best Practices State Spending Recommendation: & $\$ 59,600,000$ \\
\hline Percentage of CDC Recommended Level: & $11.8 \%$ \\
\hline State Tobacco-Related Revenue: & $\$ 477,400,000$ \\
\hline
\end{tabular}

\section{Smokefree Air:}

B

Government Worksites: Prohibited

Private Worksites: Prohibited

Schools: Prohibited

Child Care Facilities: Prohibited

Restaurants: Prohibited

Bars: No provision

Casinos/Gaming Establishments: Restricted (tribal establishments exempt)

Retail Stores: Prohibited

Recreational/Cultural Facilities: Prohibited

Penalties:Yes

Enforcement: Yes

Preemption: No

Citation: LA REV. STAT. ANN. $\S \S 40: 1291.1$ to 1291.24 (2015).

Tobacco Taxes :

$\mathrm{F}$

CIGARETTE TAX

Tax Rate per pack of 20:

$\$ 1.08$

OTHER TOBACCO PRODUCT TAXES:

Tax on little cigars: Equalized: No; Weight-Based: No

Tax on large cigars: Equalized: No; Weight-Based: No

Tax on smokeless tobacco: Equalized: No; Weight-Based: No

Tax on pipe/RYO tobacco: Equalized: Yes; Weight-Based: No

Tax on Dissolvable tobacco: Equalized: No; Weight-Based: No

Access to Cessation Services : F

OVERVIEW OF STATE CESSATION COVERAGE:

STATE MEDICAID PROGRAM:

Medications: Covers all 7 medications

Counseling: Covers limited counseling

Barriers to Coverage: Some barriers exist to access care

Medicaid Expansion: Yes

STATE EMPLOYEE HEALTH PLAN(S) 
Medications: Covers all 7 medications

Counseling: Covers limited counseling

Barriers to Coverage: Some barriers exist to access care

STATE QUITLINE:

Investment per Smoker: $\$ 0.97$; the median investment per smoker is $\$ 2.10$

OTHER CESSATION PROVISIONS:

Private Insurance Mandate: Insurance Commissioner bulletin

Tobacco Surcharge: No prohibition or limitation on tobacco surcharges

\begin{tabular}{|l|l|}
\hline Minimum Age: & F \\
\hline Minimum Age of Sale for Tobacco Products: & 18 \\
\hline
\end{tabular}

*Tables extracted from http://www.lung.org/assets/documents/tobacco/state-of-tobacco-control.pdf

\section{Methodology}

This study was mainly carried as a literature research methodology. Literature research methodology also referred to as the "non-contact method" by Guijuan Lin, (2009) is reading through, analyzing and sorting literature to identify essential attributes. It is described as the non-contact method because unlike other research methodologies which directly deal with the object under study, it does not directly deal with the object under study but gains an indirect an access to information from a variety of literature.

The databases used to search for literature used in this study were EBSCO, PsyINFO, JSTOR, PUBMED, Science Direct, and Google/Google Scholar. For the easy identification of relevant papers, the search was carried out using the terms:Health promotion, tobacco control, Louisiana. The data was analyzed by content analysis.

\section{Demonstrated in Flow Diagram.}

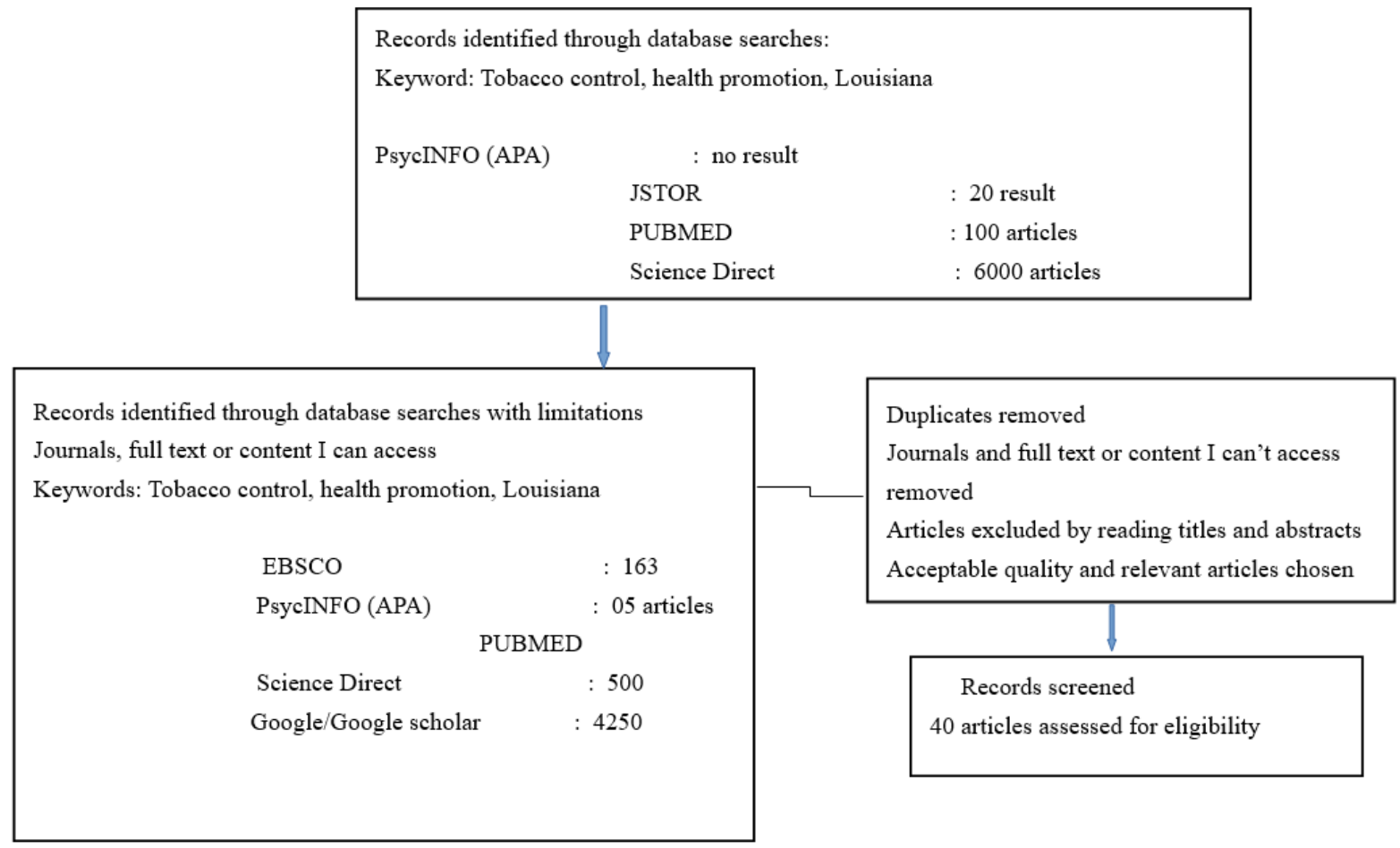

\section{Health Promotion Methods}

1. Fax-To-Quit

The Fax-To-Quit Louisiana program is a Health Systems approach designed to increase provider's adherence to the Public Health Service Clinical Practice Guidelines in treating tobacco dependence and use. After providing brief intervention to their patients for tobacco cessation, through fax-referral using Fax-To-Quit Louisiana 
program, clinicians can refer patients to the LA Tobacco Quit line that provides free tobacco cessation counseling to Louisiana residents 13 years and older (patient who are 13 to 17 years old, do not need parental consent to receive LA Tobacco Quit line counseling). Tobacco cessation counseling by LA Tobacco Quit line is at no cost to the patient or the referring clinician (SWLAHEC, 2018)

\section{Quit-With-Us La}

The Quit- with-us or Louisiana Tobacco Quitline links people who want to quit using tobacco with trained tobacco cessation specialists who create an individualized plan to quit. It is a confidential, free tobacco cessation helpline that operates 24 hour a day, seven days a week to all Louisiana residents over age 13, but the number of coaching sessions offered may be limited and is based on certain qualifications, such as pregnancy or the type of insurance coverage. This service is available in English, Spanish, and 150 other languages to people calling from anywhere in Louisiana and it is Free. Tobacco users who call the Louisiana Tobacco Quitline receive: a One free, proactive counseling session with a tobacco cessation specialist, a free self-help guide and tools with support materials and information on programs in their area (the area of the Tobacco user). The quit line is jointly managed by the Louisiana Tobacco Control Program (administered by DHH) and the non-profit Louisiana Campaign for Tobacco-Free Living. Program participants receive free coaching and support through certified quit coaches who work with each caller to develop a personalized quit plan. Through the DHH pilot program, state employees qualify for up to five scheduled coaching sessions as well as web-based services through the Quitline's web coach program. The pilot program is made possible through a federal grant from the U.S. Centers for Disease Control and Prevention (http://quitwithusla.org, 2018)

\section{Louisiana State University Health System's Tobacco Control Initiative}

The Tobacco Control Initiative (TCI)'s goal is to reduce tobacco use among the patient population of the 10 LSU health system public hospitals. The initiative was by a legislatively-enacted cigarette excise tax as part of a statewide tobacco control program funded by the government (LSU Health System, 2015). By using a health system change approach, evidence based clinical interventions and treatments were integrated into patient care practices at all 10 sites. The TCI is an example of a real-world implementation project with a research component. Results of the health systems approach work at LSU health system public hospitals. The TCI management team provides state tobacco control programs with additional details about how the TCI team developed and implemented this systems approach among their hospitals, as well as outcomes they have seen from their work. (CDC, 2015)

At the system level, TCI's goals were to implement electronic identification and documentation of tobacco use status and treatment in all 10 facilities, and to train providers across all facilities to conduct evidence-based tobacco treatment interventions. At the clinician level, TCI's goals were to (1) have physicians ask $100 \%$ of their patients about tobacco use; (2) advise $90 \%$ of identified tobacco users to quit; (3) assess $90 \%$ of identified tobacco users for readiness to quit; (4) assist 75\% of identified tobacco users who say they are ready to quit in a quit attempt by using behavioral counseling and/or medication; and (5) arrange follow-up contact for 50\% of tobacco users who make a quit attempt. At the patient level, TCI's goals were to have $40 \%$ of tobacco users use evidence-based treatment (medications, in-house behavioral counseling, and/or quitline services), and to increase the annual quit rate to $10 \%$ (Louisiana State University Health System, 2015)

\section{Conclusion}

Tobacco dependence is a chronic disease, but it isn't always treated or viewed as one. The U.S. Department of Health and Human Services reports that "modern approaches to treating tobacco use and dependence should reflect the chronicity of tobacco dependence". More recent calculations from Leif Associates, Inc. estimate that smokers have health care costs averaging nearly 34\% higher than nonsmokers (Walque, 2004). These programs include an anti-tobacco marketing campaign, school- and community-based prevention activities, tobacco cessation programs tailored to teens, and efforts to strengthen tobacco-free norms and protect children and nonsmokers from secondhand smoke through tobacco-free policies. These efforts are supported by local youth groups who share information about the dangers of tobacco use, expose tobacco industry marketing techniques, and educate about the benefits of tobacco-free policies. (Frank J, 2012).

Tobacco use can lead to tobacco/nicotine dependence and serious health problems. Quitting smoking greatly reduces the risk of developing smoking-related diseases.

(Fiore, 2008)

Benefits of quitting

- $\quad$ Lowered risk for lung cancer and many other types of cancer.

- $\quad$ Reduced risk for heart disease, stroke, and peripheral vascular disease.

- $\quad$ Reduced heart disease risk within 1 to 2 years of quitting.

- Reduced respiratory symptoms, such as coughing, wheezing, and shortness of breath. While these 
symptoms may not disappear, they do not continue to progress at the same rate among people who quit compared with those who continue to smoke.

- $\quad$ Reduced risk of developing some lung diseases (such as chronic obstructive pulmonary disease, also known as COPD, one of the leading causes of death in the United States). (De Walque, 2004)

- $\quad$ Reduced risk for infertility in women of childbearing age. Women who stop smoking during pregnancy also reduce their risk of having a low birth weight baby.

The tobacco prevention and control which is aimed ending tobacco dependence has mainly three quitting resources which are the Fax-to-quit, the online coaching service (Frank J, 2012).

\section{REFERENCES}

1. de Walque, D. (2004). "Education, information and smoking decisions: evidence from smoking histories, 1940-2000."

2. Hurd, M., D. et al (2001). "Predictions of Mortality Among the Elderly." In Themes in the Economics of Aging, edited by D. Wise, pages 171-197. University of Chicago Press.

3. Kawachi, I., et al (1997). "Smoking Cessation and Decreased Risks Of Total Mortality, Stroke, and Coronary Heart Disease Incidence Among Women: A Prospective Cohort Study." In Monograph 8: Changes in Cigarette-Related Disease Risks and Their Implications for Prevention and Control, edited by D. M. Burns, L. Garfinkel, and J. M. Samet, volume 8 of Smoking and Tobacco Control Monographs, chapter 8, pages 531-565. National Cancer Institute

4. Khwaja, A., F. Sloan, and S. Chung (2007). "The Relationship Between Individual Expectations and Behaviors: Mortality Expectations and Smoking Decisions." forthcoming, Journal of Risk and Uncertainty.

5. Fertig, A. (2010). "Selection and the Effect of Prenatal Smoking." Health Economics, 19, 209- 226.

6. Lahiri, K. and J. G. Song (2000). "The effect of smoking on health using a sequential selfselection model." Health Economics, 9(6), 491-511. Lien, D. S. and W. N. Evans (2005). "Estimating the Impact of Large Cigarette Tax Hikes: The Case of Maternal Smoking and Infant Birth Weight." Journal of Human Resources, 40(2), 373-392.

7. $\quad$ "Prevalence of current tobacco use among adults aged=15 years (percentage)". World Health Organization

8. Kroon LA (2007). "Drug interactions with smoking".Am J Health Syst Pharm.64 (18): 1917-1921. doi:10.2146/ajhp060414. PMID 17823102

9. Mahid SS, et al (Nov 2006). "Smoking and inflammatory bowel disease: a meta-analysis".Mayo Clinic Proceedings.81 (11): 1462-1471. doi:10.4065/81.11.1462. PMID17120402.

10. Missmer SA, et al (Oct 2004). "Incidence of laparoscopically confirmed endometriosis by demographic, anthropometric, and lifestyle factors". American Journal of Epidemiology. 160 (8): 784796.doi:10.1093/aje/kwh275. PMID 15466501.

11. Baron JA (Jan 1996). "Beneficial effects of nicotine and cigarette smoking: the real, the possible and the spurious".British Medical Bulletin. 52 (1): 58-73.doi:10.1093/oxfordjournals.bmb.a011533. PMID 8746297

12. Sørensen LT (Apr 2012). "Wound healing and infection in surgery. The clinical impact of smoking and smoking cessation: a systematic review and meta-analysis".Archives of Surgery.1 47 (4): $373-83$. doi:10.1001/archsurg.2012.5. PMID 22508785.

13. Boffetta P (Sep 2008). "Tobacco smoking and risk of bladder cancer". Scandinavian Journal of Urology and Nephrology. Supplementum. 42 (218): 45-54.doi:10.1080/03008880802283664. PMID18815916.

14. "Esophagus Cancer". American Cancer Society. 2011-08-11.

15. Iodice S, et al (Jul 2008). "Tobacco and the risk of pancreatic cancer: a review and meta-analysis". Langenbeck's Archives of Surgery / Deutsche Gesellschaft Für Chirurgie. 393 (4): 535545.doi:10.1007/s00423-007-0266-2.PMID 18193270.

16. Kuper H, et al (Sep 2002). "Tobacco use and cancer causation: association by tumour type".Journal of Internal Medicine. 252 (3): 206-224.doi:10.1046/j.1365-2796.2002.01022.x. PMID 12270001.

17. Vineis, P; et al (21 January 2004). "Tobacco and cancer: recent epidemiological evidence.". Journal of the National Cancer Institute.96 (2): 99-106. doi:10.1093/jnci/djh014. PMID 14734699

18. U.S. Department of Health and Human Services. Let's Make the Next Generation Tobacco-Free: Your Guide to the 50th Anniversary Surgeon General's Report on Smoking and Health. [PDF-795 KB] Atlanta: U.S. Department of Health and Human Services, Centers for Disease Control and Prevention, National Center for Chronic Disease Prevention and Health Promotion, Office on Smoking and Health, 2014.

19. U.S. Department of Health and Human Services. The Health Consequences of Involuntary Exposure to Tobacco Smoke: A Report of the Surgeon General. Utah: U.S. Department of Health and Human Services, Centers for Disease Control and Prevention, National Center for Chronic Disease Prevention and Health Promotion, Office on Smoking and Health, 2006.

20. U.S. Department of Health and Human Services. A Report of the Surgeon General: How Tobacco Smoke 
Causes Disease: What It Means to You.Utah: U.S. Department of Health and Human Services, Centers for Disease Control and Prevention, National Center for Chronic Disease Prevention and Health Promotion, Office on Smoking and Health, 2010.

21. U.S. Department of Health and Human Services. The Health Consequences of Smoking-50 Years of Progress: A Report of the Surgeon General.Atlanta: U.S. Department of Health and Human Services, Centers for Disease Control and Prevention, National Center for Chronic Disease Prevention and Health Promotion, Office on Smoking and Health, 2014

22. Institute of Medicine. Secondhand Smoke Exposure and Cardiovascular Effects: Making Sense of the Evidence [PDF-707.47 KB]. Washington: National Academy of Sciences, Institute of Medicine, 2009

23. U.S. Department of Health and Human Services (2004). The Health Consequences of Smoking: A Report of the Surgeon General. Atlanta: U.S. Department of Health and Human Services, Centers for Disease Control and Prevention, National Center for Chronic Disease Prevention and Health Promotion, Office on Smoking and Health, 2004

24. Fiore MC, Jaén CR, Baker TB, et al (2008). Treating Tobacco Use and Dependence: 2008 UpdateClinical Practice Guidelines. Rockville (MD): U.S. Department of Health and Human Services, Public Health Service, Agency for Healthcare Research and Quality, National Toxicology Program. Report on Carcinogens, Thirteenth Edition. Research Triangle Park (NC):

25. U.S. Department of Health and Human Sciences, National Institute of Environmental Health Sciences, National Toxicology Program, 2014

26. U.S. Department of Health and Human Services. The Health Consequences of Smoking: A Report of the Surgeon General. Atlanta: U.S. Department of Health and Human Services, Centers for Disease Control and Prevention, National Center for Chronic Disease Prevention and Health Promotion, Office on Smoking and Health, 2004

27. "The health consequences of involuntary exposure to tobacco smoke: a report of the Surgeon General" (PDF). Atlanta, U.S., page 93: U.S. Department of Health and Human Services, Centers for Disease Control and Prevention, National Center for Chronic Disease Prevention and Health Promotion, Office on Smoking and Health. 2006.

28. CDC, Youth Risk Behavior $\quad$ Surveillance $\quad$ System, 2017. https://www.cdc.gov/healthyyouth/data/yrbs/index.htm

29. CDC, State-Specific Prevalence of Tobacco Product Use Among Adults - United States, 2014-2015, MMWR. https://www.cdc.gov/mmwr/volumes/67/wr/mm6703a3.htm

30. Campaign for Tobacco-Free Kids, Broken Promises to Our Children: a State-by-State Look at the 1998 State Tobacco Settlement 19 Years Later FY2018, 2017. accessed at https://www.tobaccofreekids.org/whatwe-do/us/statereport

31. Campaign for Tobacco-Free Kids, Toll of Tobacco in the United States, 2018 accessed at https://www.tobaccofreekids.org/what-we-do/us/statereport

32. American Lung Association, SLATI State Reports, 2017 accessed at http://www.lung.org/ourinitiatives/tobacco/reports-resources/sotc/

33. American Lung Association, State of Tobacco Control, 2018 accessed at http://www.lung.org/ourinitiatives/tobacco/reports-resources/sotc/

34. Campaign for Tobacco-Free Kids, State Cigarette Excise Tax Rates \& Rankings, 2018 accessed at https://www.tobaccofreekids.org/assets/factsheets/0097.pdf

35. CDC, Behavioral Risk Factor Surveillance System, State Tobacco Activities Tracking and Evaluation System, 2017 accessed at https://www.cdc.gov/brfss/index.html

36. Golechha, M. (2016). Health Promotion Methods for Smoking Prevention and Cessation: A Comprehensive Review of Effectiveness and the Way Forward. International Journal of Preventive Medicine,7, 7. http://doi.org/10.4103/2008-7802.173797

37. Louisiana State University Health System. LSU health annual report. http://www.lsuhospitals.org/docs/LSU_AnnualReport2010.pdf. Accessed January 7, 2015.

38. Guiljuan Lin (2009), Higher Education Research Methodoly- Literature Method. International education studies.

39. The Health Consequences of Involuntary Exposure to Tobacco Smoke: A Report of the Surgeon General, 2006

EPA, Secondhand Smoke: What You Can Do About Secondhand Smoke As Parents, Decision-Makers, and Building Occupants, July 1993; Health Effects of Exposure to Environment Tobacco Smoke, California EPA report, 1997,http://www.oehha.org/air/environmental tobacco/finalets.html

40. Canadian Cancer Society, http://www.cancer.ca/ccs/internet/standard/0,3182,3172_13127_langIden, $00 . \mathrm{html}$ 